Research Article

\title{
Comprehensive Evaluation of the Accelerated Aging Law of NEPE Propellants
}

\author{
Yulong Liang, Mi Zhang, Hui Ren $(\mathbb{D}$, and Qingjie Jiao \\ State Key Laboratory of Explosion Science and Technology, Beijing Institute of Technology, Beijing 100081, China \\ Correspondence should be addressed to Hui Ren; renhui@bit.edu.cn
}

Received 3 August 2020; Revised 1 September 2020; Accepted 22 September 2020; Published 5 October 2020

Academic Editor: Tifeng Jiao

Copyright (C) 2020 Yulong Liang et al. This is an open access article distributed under the Creative Commons Attribution License, which permits unrestricted use, distribution, and reproduction in any medium, provided the original work is properly cited.

In order to study the accelerated aging law of nitrate ester plasticized polyether (NEPE) propellants, the mechanical properties, weight loss, adhesive network structure fracture, and stability of NEPE propellants during storage were analyzed. The results show that the maximum tensile strength $\sigma_{m}$ shows good change law with the increase of storage time, and the failure of NEPE propellants is mainly strength failure. The content of the stabilizer decreased with the increase of storage time. With the prolongation of storage time, the weight loss ratio increases gradually with good regularity. The decomposition of the components in the propellant leads to the degradation of the polyethylene glycol (PEG) network structure. The thermal decomposition of the nitrate plasticizer in NEPE propellants will occur, and the products will cause the adhesive network structure to decompose and break the chain, leading to the destruction of the matrix structure. The thermal decomposition of the propellant has temperatureincreasing rate dependency.

\section{Introduction}

Solid rocket engines are important defense products, and the health status has a critical impact on weapon reliability. To a large extent, the storage life of solid rocket engines depends on the storage properties of solid propellants, including physical and chemical properties, internal ballistic performance, and structural integrity [1]. However, the solid propellant is an unstable material that will cause physical and chemical aging during long-term storage [2]. Physical aging refers to changes in the physical properties of solid propellants during the storage periods, such as moisture absorption, dehumidification between the oxidant and the binder interface, solvent vitalization, debonding between the propellant and the liner, cracks and voids caused by stress or strain, and other changes in physical properties. Chemical aging refers to the change in properties of solid propellants caused by chemical changes during processing, storage, and use, such as thermal decomposition, hydrolysis, degradation, decomposition of oxidants, oxidative crosslinking, and degradation of adhesives. The chemical changes caused by the interaction of various components of the propellant or reaction with the air are irreversible, and the rate of change varies with different storage conditions. Therefore, the study of the solid propellant aging mechanism is the basis of its storage life assessment and an important issue in the life prediction of solid rocket engines [3-5].

NEPE combines the advantages of the double-base propellant and composite propellant. It is a new type of propellant with excellent energy performance and mechanical properties at present and represents the development direction of high-energy solid propellants [6-8]. However, in the storage process, this type of propellant is prone to complex aging phenomena, causing engine failure and leading to safety risks and economic losses [9-11]. Therefore, it is necessary to carry out an in-depth analysis of the aging performance characteristics of NEPE propellants to provide a theoretical basis for the next step in finding effective antiaging measures. In the article, we analyze the storage performance of NEPE solid propellants, explore the accelerated aging rules of NEPE propellants, and study their health detection technology. 


\section{Materials and Characterization}

The NEPE propellant used in the experiment adopts the general PEG/N100 system, and the propellant uses mixed nitrate (a mixture of NG and BTTN) as a plasticizer. First, propellant slurry is cast into a certain size of the propellant sample, and then a certain shape and size of the sample are prepared. Propellant mechanical property test specimens are prepared according to type B specimens in GJB770B-2005 method 413.1, "maximum tensile strength, breaking strength, maximum elongation, and breaking elongation unidirectional tension method," and the accelerated storage test specimens are a $120 \mathrm{~mm} \times 120 \mathrm{~mm} \times 10 \mathrm{~mm}$ sheet sample. Propellant adhesive test pieces were prepared in proportion with PEG, N100, and mixed nitrate.

The DU288 oil bath oven of Shanghai Experimental Instrument Factory Co., Ltd., was used to carry out the accelerated storage test, and the oven temperature uniformity was $\leq 2^{\circ} \mathrm{C}$. The Instron 5567 tensile machine made in the United States was used to test the maximum tensile strength $\sigma_{m}$ and maximum elongation $\varepsilon_{m}$ of the propellant in different aging processes at $25^{\circ} \mathrm{C}$. The test method follows GJB770B-2005 method 413.1, and the stretching rate is $100 \mathrm{~mm} / \mathrm{min}$. The thermoelectric company Nicolet 6700 Fourier-transform infrared spectrometer was used to analyze the functional group changes during the storage of the adhesive system. The DSC204F1 differential thermal scanning calorimeter of the German NETZSH company was used to analyze the thermal decomposition performance of the sample, and the heating rate was $5^{\circ} \mathrm{C} / \mathrm{min}, 10^{\circ} \mathrm{C} / \mathrm{min}$, $15^{\circ} \mathrm{C} / \mathrm{min}$, and $20^{\circ} \mathrm{C} / \mathrm{min}$. The Mettler Toledo XP404S weighing balance was used to test the weightlessness of samples during the aging process. The $\mathrm{FGD} 2-\mathrm{B}-\mathrm{NO}_{\mathrm{x}}$ nitrogen oxide ananlyzer was used to test the $\mathrm{NO}_{\mathrm{x}}$ gas released from the sample, and the FGD2-B-CO2 carbon dioxide detector was used to test $\mathrm{CO} 2$ gas.

\section{Results and Discussion}

3.1. Mechanical Properties of the NEPE Propellant during Accelerated Storage. NEPE propellant accelerates aging at $55^{\circ} \mathrm{C}, 60^{\circ} \mathrm{C}, 65^{\circ} \mathrm{C}$, and $70^{\circ} \mathrm{C}$, and the changes in the maximum tensile strength $\sigma_{m}$ and the maximum elongation $\varepsilon_{m}$ with the aging time during accelerated storage are tracked and measured, which are shown in Figure 1. Figure 2 shows the change of the stabilizer content in the propellant with aging time.

As shown in Figure 1, in the process of thermally accelerated aging at different temperatures, the maximum tensile strength value fluctuates within a small range in the initial stage of aging and decreases rapidly in the later stage. And as the aging temperature increased, the time for the maximum tensile strength value to decrease shortened. Figure 2 shows that stabilizers are continuously consumed as the aging time increases. Comparing the maximum tensile strength and the stabilizer content change chart, it can be seen that the maximum tensile strength fluctuates within a small range before the stabilizer is completely consumed, but the maximum tensile strength begins to reduce rapidly after the stabilizer is consumed. It is speculated that the change law of the maximum tensile strength is related to the stabilizer content in the propellant. The initial stage is that the stabilizer is consumed by the nitrate decomposition products. In this stage, the stabilizer continuously reacts with nitrogen oxides decomposed by nitrate to form a nitroso product, which inhibits the decomposition of nitrate. When the stabilizer is consumed, nitrate decomposition products act on nitrate for the autocatalytic reaction, and the mechanical properties decrease rapidly.

At the initial stage, there is an obvious rising process of $\varepsilon_{m}$, which is mainly caused by the physical tensile action of constant strain. The reason may be that the polymer chain of the NEPE propellant binder matrix is degraded, and the chain scission effect is strengthened under the action of constant strain, which improves the elongation of the propellant. Under the action of constant strain, the polymer chains are unfolded from the collapsed state, the chains are oriented and rearranged, and the molecular chains are oriented more in the direction of the force, which increases the elongation of the propellant to a certain extent. In the later stage of aging, the influence of aging of the adhesive matrix and the dehumidification of the interface between the adhesive matrix and the solid filler is gradually significant. With the occurrence of the dehumidification phenomenon, the physical or chemical adsorption force between the dispersed phase and the continuous phase decreases, which weakens the stress transmission in the entire system and causes the maximum elongation of the propellant to decrease.

Based on the changes in the maximum tensile strength and the maximum elongation of NEPE propellants, it is shown that the failure of NEPE propellants is mainly strength failure.

Figure 3 is the state diagram of the NEPE propellant after accelerated storage. It indicated that the matrix structure became soft and bulging, and pores were present during the later accelerated storage period of the NEPE propellant. The appearance of pores indicates the emergence of gas inside the propellant. The polymer chain of the propellant will undergo a chain scission reaction. Under the condition of accelerated aging, the chemical reaction rate of chain scission will increase and be accompanied by gas precipitation. Then, the pores of the propellant matrix will appear.

3.2. Weight Loss in the Process of Accelerated Storage. The thermal weight loss during accelerated storage of the NEPE propellant and hydroxyl-terminated polybutadiene (HTPB) propellant is compared, which is shown in Figure 4.

NEPE propellant is aged by storing at $70^{\circ} \mathrm{C}$, and its weight loss rate gradually increased with the extension of storage time and reached about $10 \%$ when stored for 140 days $(3360 \mathrm{~h})$, which has not yet reached the limit. It indicates that the NEPE propellant will undergo a significant decomposition reaction when stored at $70^{\circ} \mathrm{C}$, but for the HTPB propellant, the value of weight loss is almost constant. For the thermal parameters for the NEPE propellant, the regularity between weight loss rate and storage time is great, 


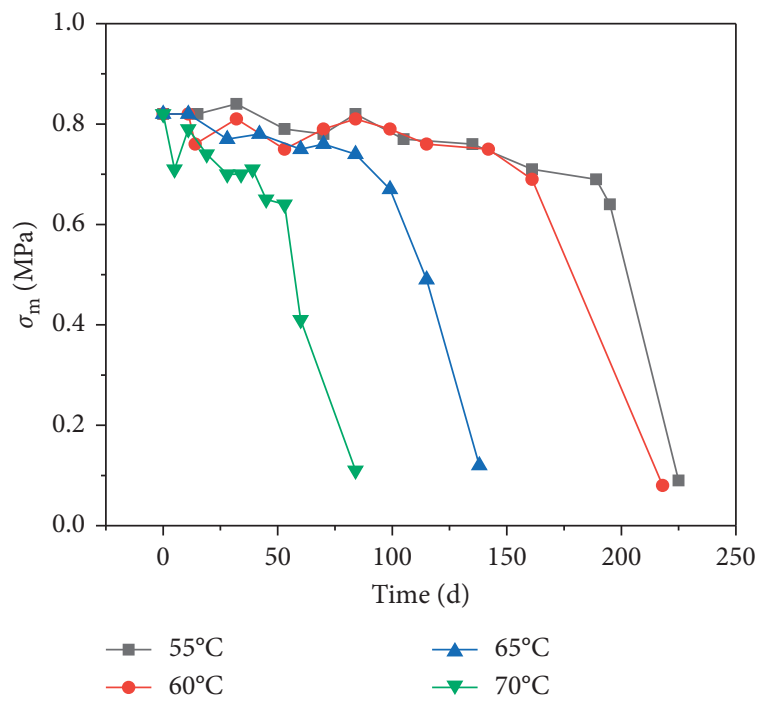

(a)

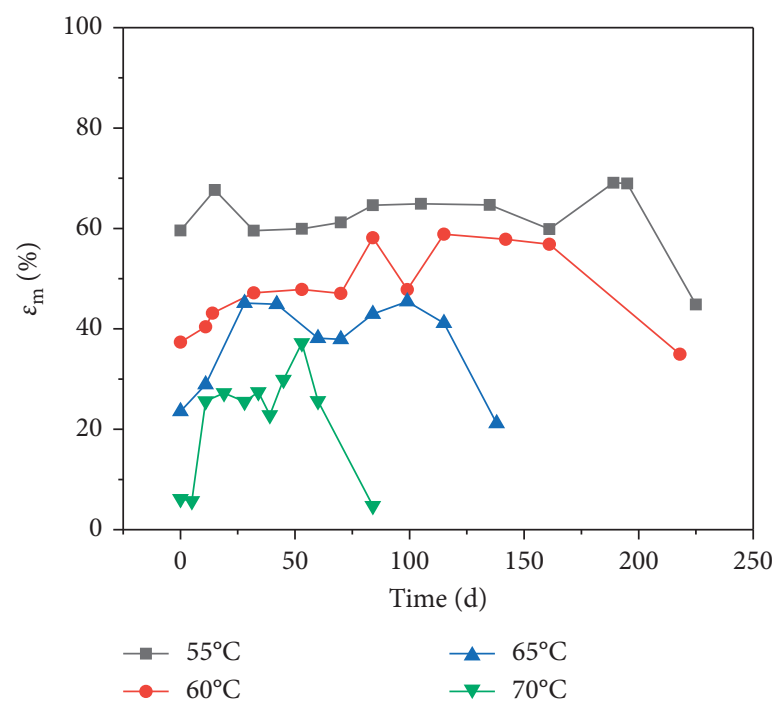

(b)

FIgURE 1: The change rule of $\sigma_{m}$ and $\varepsilon_{m}$ of NEPE at different storage temperatures.

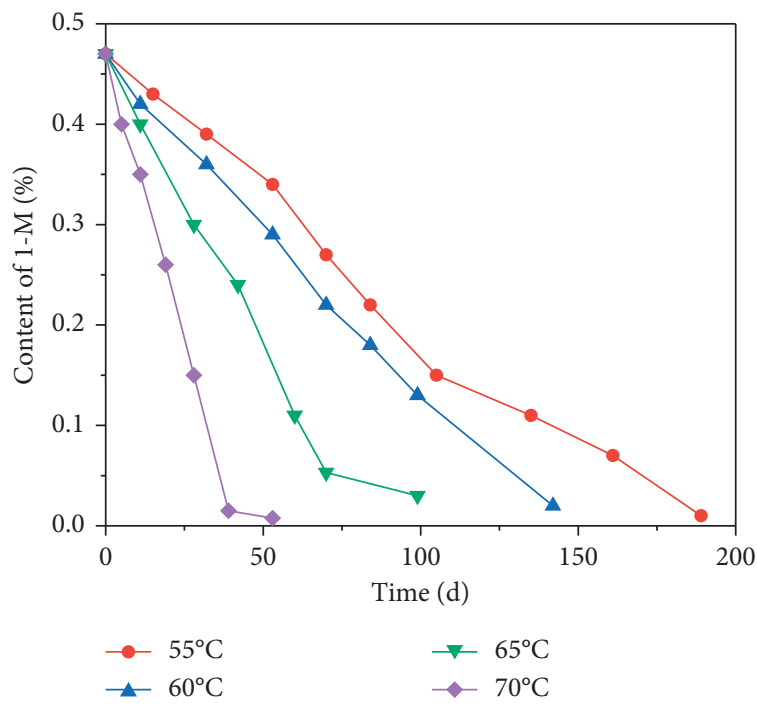

(a)

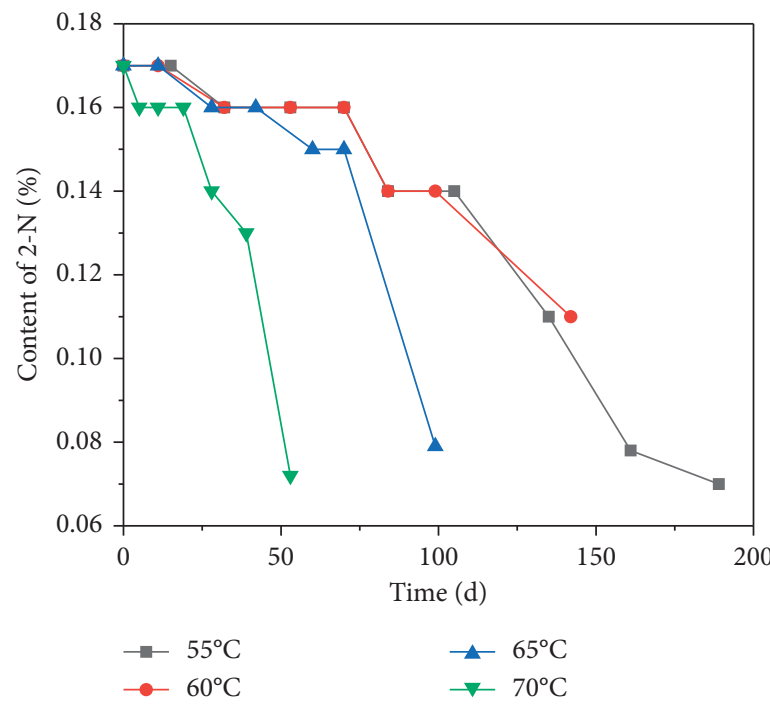

(b)

FIgURE 2: The content of the stabilizer at different storage temperatures.

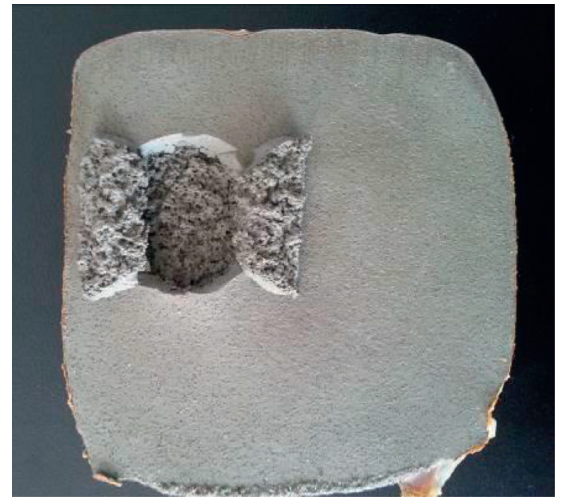

FIgURE 3: The state diagram of NEPE after accelerated storage. and the detection of the weight loss rate is easy to implement. Therefore, the weight loss rate can be used as a health monitoring index for similar propellants.

3.3. Adhesive Network Structure Fracture Test. Two groups of NEPE propellant adhesive samples were selected for the $80^{\circ} \mathrm{C}$ storage test. One group is PEG adhesive films. The other group is composed of PEG adhesive films and NEPE propellants. Figure 5 shows the PEG adhesive film before and after storage. Figure 6 exhibits the state of storage of the NEPE propellant with the PEG adhesive network structure before and after storage. 


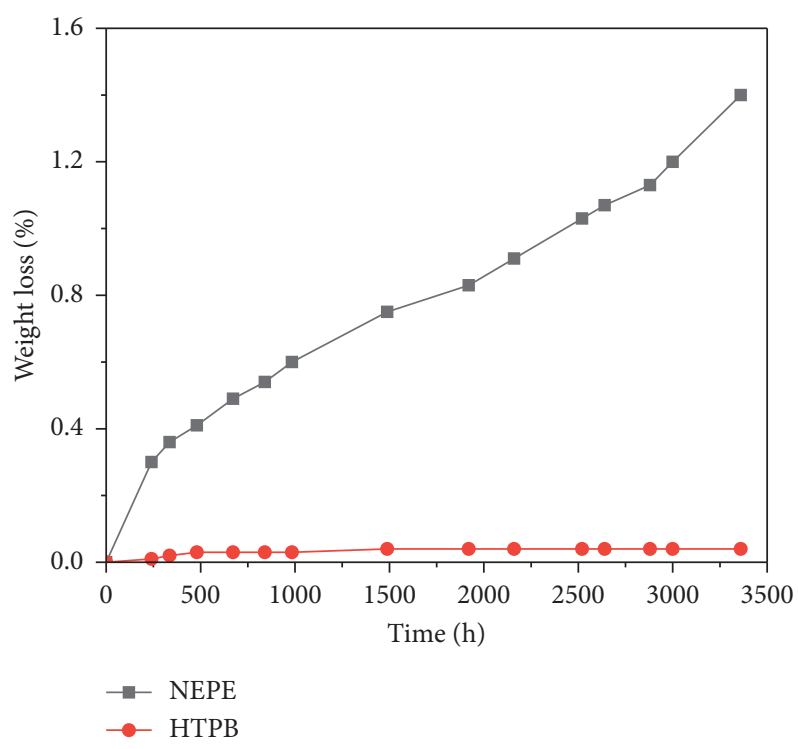

FIGURE 4: Comparison of the thermal weight loss of the NEPE propellant and hydroxyl-terminated polybutadiene propellant during accelerated storage at $70^{\circ} \mathrm{C}$.

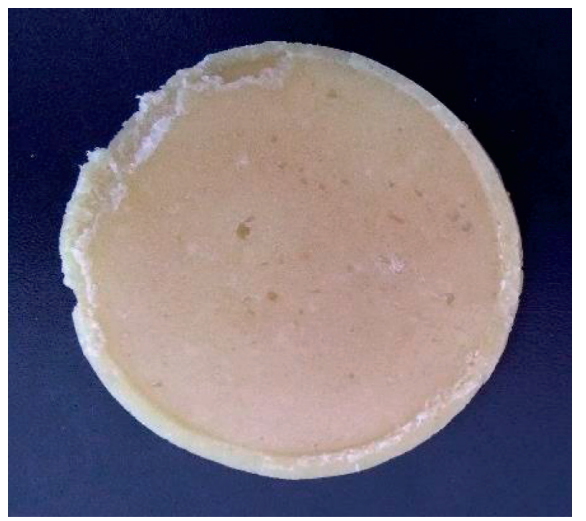

(a)

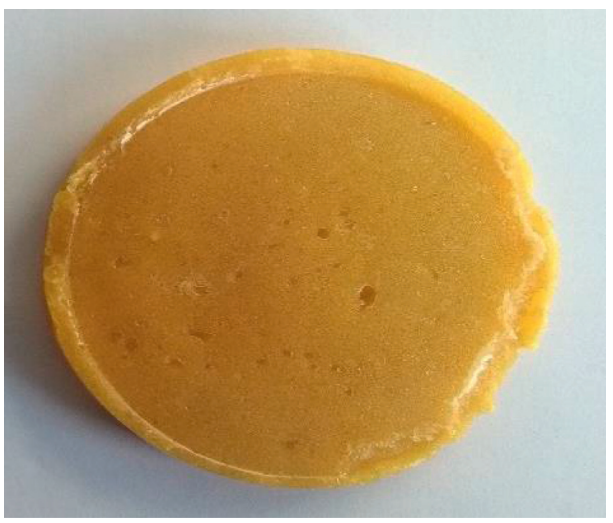

(b)

FIGURE 5: The images of the PEG adhesive film before (a) and after (b) storage.

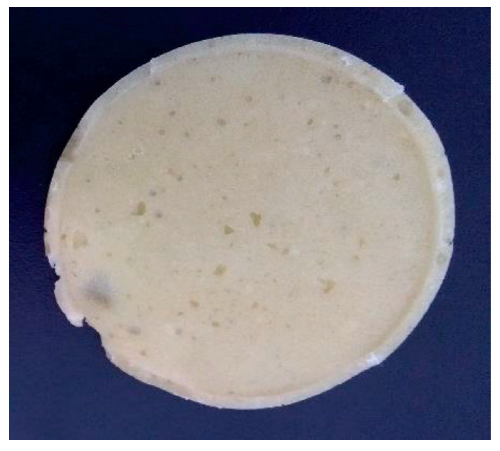

(a)

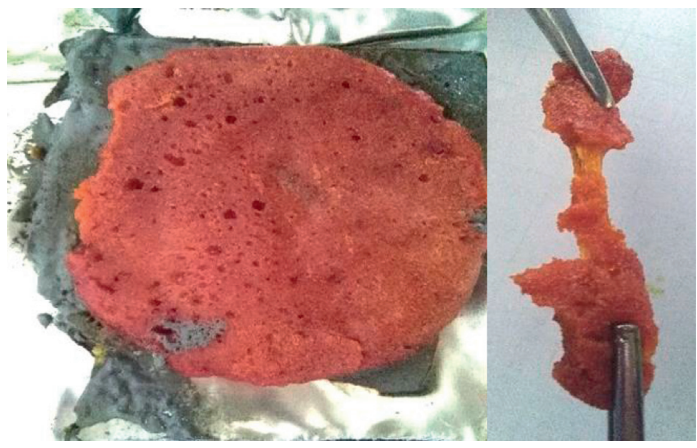

(b)

FIGURE 6: The images of storage of the NEPE propellant with the PEG adhesive network structure: before (a) and after (b). 
TABLE 1: Gas release during accelerated aging of the NEPE propellant.

\begin{tabular}{|c|c|c|c|c|c|c|c|c|}
\hline \multicolumn{3}{|c|}{$50^{\circ} \mathrm{C}$} & \multicolumn{3}{|c|}{$60^{\circ} \mathrm{C}$} & \multicolumn{3}{|c|}{$70^{\circ} \mathrm{C}$} \\
\hline \multirow{2}{*}{ Time of storage $(\mathrm{d})$} & \multicolumn{2}{|c|}{ Gas release } & \multirow{2}{*}{ Time of storage $(\mathrm{d})$} & \multicolumn{2}{|c|}{ Gas release } & \multirow{2}{*}{ Time of storage (d) } & \multicolumn{2}{|c|}{ Gas release } \\
\hline & $\mathrm{NO}_{\mathrm{x}}(\mathrm{ppm})$ & $\mathrm{CO}_{2}(\%)$ & & $\mathrm{NO}_{\mathrm{x}}(\mathrm{ppm})$ & $\mathrm{CO}_{2}(\%)$ & & $\mathrm{NO}_{\mathrm{x}}(\mathrm{ppm})$ & $\mathrm{CO}_{2}(\%)$ \\
\hline 23 & 1.4 & 0.9 & 20 & 1.3 & 1.7 & 17 & 7.8 & 3.6 \\
\hline 53 & 2.8 & 1.0 & 34 & 1.5 & 2.4 & 25 & 5.7 & 4.9 \\
\hline 105 & 3.9 & 0.9 & 48 & 26 & 5.9 & 42 & 280 & 25.9 \\
\hline 124 & 23 & 2.3 & 72 & 346 & 7.6 & 48 & 842 & 32 \\
\hline 158 & 89 & 5.6 & 136 & 1508 & 15.7 & 52 & 1216 & 43 \\
\hline 206 & 212 & 7.8 & 183 & 3860 & 23.7 & 62 & 5000 & 51 \\
\hline
\end{tabular}

It can be seen from Figure 5 that matrix color turns yellow, and the structure has not changed after the single film is stored thermally. Figure 6 shows that the film and propellant are stored together for thermal storage, the PEG adhesive undergoes a significant degradation reaction, and the adhesive network structure is damaged. After degradation, the adhesive loses its original mechanical strength. The results indicate that the decomposition of components in the propellant leads to the degradation of the PEG network structure during the thermal storage of the NEPE propellant.

\subsection{Changes of NEPE Propellant Aging and Degradation} Release Gas. In the NEPE propellant accelerated storage experiment, the amount of gas in the sealed bag is regularly detected, and the result is shown in Table 1. Figure 7 exhibits the variation of $\mathrm{NO}_{\mathrm{x}}$ and $\mathrm{CO}_{2}$ release with storage time at different temperatures.

As shown in Figure 7, the gas release rate of the propellant is faster with a higher temperature. At $70^{\circ} \mathrm{C}, \mathrm{NO}_{\mathrm{x}}$ and $\mathrm{CO}_{2}$ released by the NEPE propellant increased exponentially and began to soften after around 60 days. The content is the maximum value to maintain the structural integrity of the propellant. At $60^{\circ} \mathrm{C}$, the NEPE propellant did not soften after more than 180 days of storage. At this time, the amount of $\mathrm{NO}_{\mathrm{x}}$ released was $3860 \mathrm{ppm}$, and the amount of $\mathrm{CO}_{2}$ released was $23.7 \%$. The amount of gas released by the NEPE propellant slowly increased with the extension of storage time at $50^{\circ} \mathrm{C}$. The $\mathrm{NO}_{\mathrm{x}}$ gas detected at 206 days was $212 \mathrm{ppm}$, and the amount of $\mathrm{CO}_{2}$ was $7.8 \%$.

3.5. The Degradation Reaction of the NEPE Propellant. NEPE propellant decomposition mainly includes nitrate decomposition and polyurethane decomposition. Combined with the above experiments, the decomposition reaction process of the NEPE propellant during accelerated storage can be speculated.

The nitrate decomposition reaction process is shown as follows:

$$
\begin{aligned}
& \text { R-O- } \mathrm{NO}_{2} \longrightarrow \mathrm{R}-\mathrm{O} \cdot+\cdot \mathrm{NO}_{2} \\
& \mathrm{R}-\mathrm{O}-\mathrm{NO}_{2}+\mathrm{R}-\mathrm{O}\left(\mathrm{NO}_{2}\right) \longrightarrow \mathrm{N}_{2}, \mathrm{~N}_{\mathrm{x}} \mathrm{O}, \mathrm{H}_{2} \mathrm{O}, \mathrm{H}_{2}, \mathrm{CO}_{2}, \\
& \mathrm{CO}, \mathrm{C}_{2} \mathrm{H}_{2} \mathrm{O}_{4} \cdot \mathrm{NO}, \cdot \mathrm{NO}_{2} \\
& \mathrm{R}-\mathrm{O}-\mathrm{NO}_{2}+2 \mathrm{H}_{2} \mathrm{O} \stackrel{\mathrm{H}^{+}}{\longrightarrow} \mathrm{R}-\mathrm{OH}+\mathrm{HNO}_{3} \\
& \mathrm{NO}+\mathrm{O}_{2} \longrightarrow 2 \mathrm{NO}_{2}
\end{aligned}
$$

$$
\begin{aligned}
& \mathrm{NO}_{2}+\mathrm{NO}+\mathrm{H}_{2} \mathrm{O} \longrightarrow 2 \mathrm{HNO}_{2} \\
& \mathrm{NO}_{2}+\mathrm{H}_{2} \mathrm{O} \longrightarrow 2 \mathrm{HNO}_{3}+\mathrm{NO}
\end{aligned}
$$

The polyurethane adhesive of the NEPE propellant contains the ether group and urethane group and can react under the action of water:

$$
\mathrm{R}-\mathrm{NH}-\mathrm{CO}-\mathrm{O}-\mathrm{R}^{\prime}+\mathrm{H}_{2} \mathrm{O} \longrightarrow \mathrm{R}-\mathrm{NH}_{2}+\mathrm{R}^{\prime}-\mathrm{OH}+\mathrm{CO}_{2} \uparrow
$$

The degradation of the NEPE propellant during storage is caused by the decomposition of nitrate. $\mathrm{H}_{2} \mathrm{O}$ and $\mathrm{NO}_{\mathrm{x}}$ radicals are generated during the decomposition of nitrate, and the free radicals promote the continued decomposition of nitrate. $\mathrm{H}_{2} \mathrm{O}$ is the main factor that promotes the decomposition of adhesive polyurethane, which leads to the chain breakage of the adhesive polymer and the damaged matrix structure of the propellant. When the decomposition reaction cannot be inhibited by the stabilizer, the decomposition reaction will continue to decompose to a certain degree, the polymer chain in the adhesive network structure is generally broken, and the propellant is transformed from a softened state into pulp. Figure 8 is the sketch of structural failure caused by aging and decomposition of the NEPE propellant.

The thermal decomposition of the nitrate plasticizer in NEPE will cause the decomposition of the adhesive network structure to cause chain breakage, resulting in damage to the matrix structure. It can be known from the decomposition process of propellants that $\mathrm{NOx}$ is mainly produced by the decomposition of nitrate, and $\mathrm{CO}_{2}$ is produced by the decomposition of nitrate and binder. Therefore, $\mathrm{NO}_{\mathrm{x}}$ is used as a characteristic gas for the health characterization of propellants.

3.6. Thermal Decomposition of NEPE Propellants. TGA/DSC was used to characterize the thermal behavior of NEPE propellants at different heating rates. The results are shown in Figure 9. It demonstrates that the thermal decomposition of the propellant depends on the temperatureraising rate. As the heating rate increases, the temperature of the first decomposition peak increased, and the second decomposition peak showed almost inconspicuous change. The first decomposition peak of the propellant on DSC is a severe exothermic peak, which is the decomposition of some plasticizers (such as NG and BTTN) with HMX participation. The TG curve shows that the weight loss rates under different heating rates are about $16 \%, 23 \%, 28 \%$, and $32 \%$ in 


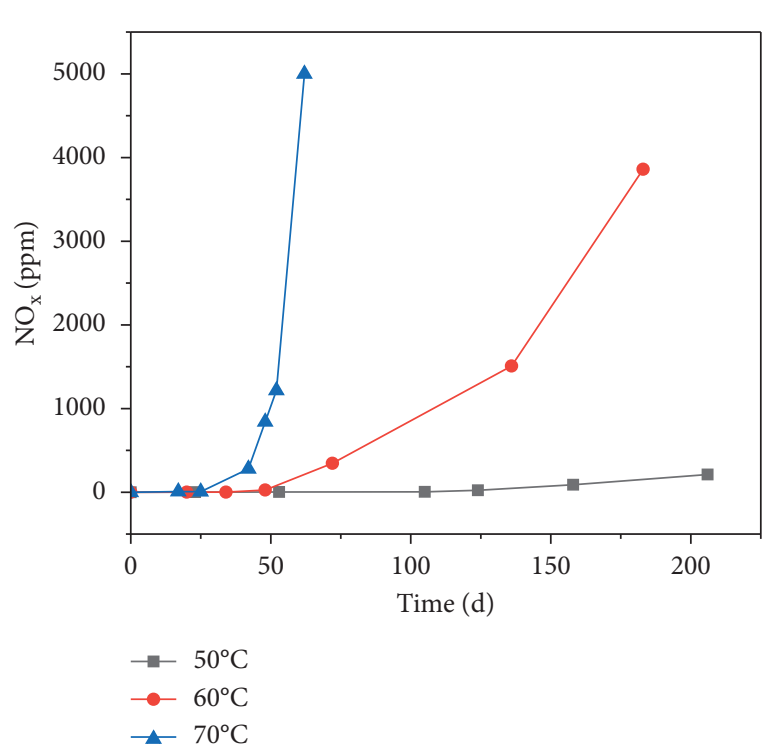

(a)

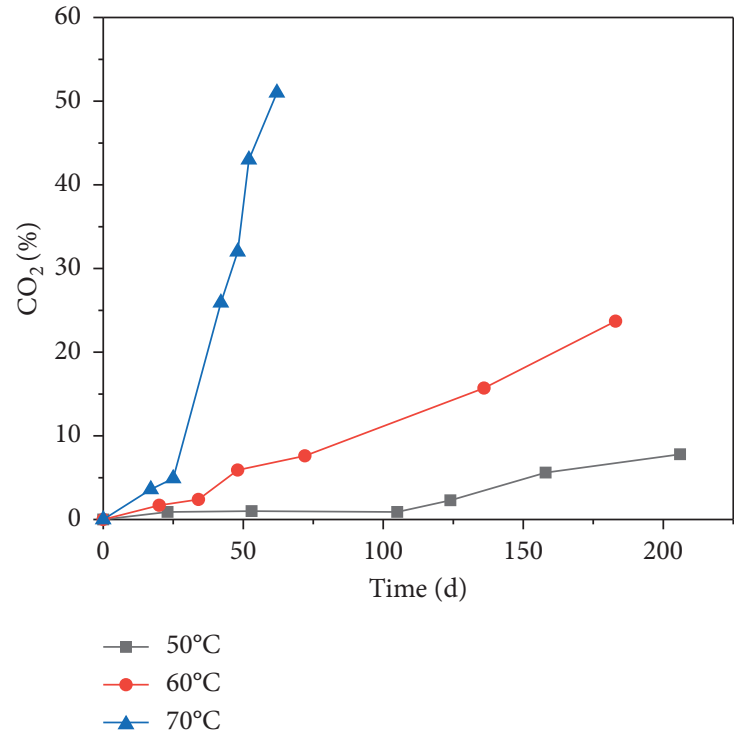

(b)

FIgURE 7: Variation of $\mathrm{NO}_{\mathrm{x}}$ and $\mathrm{CO}_{2}$ release with storage time at different temperatures.

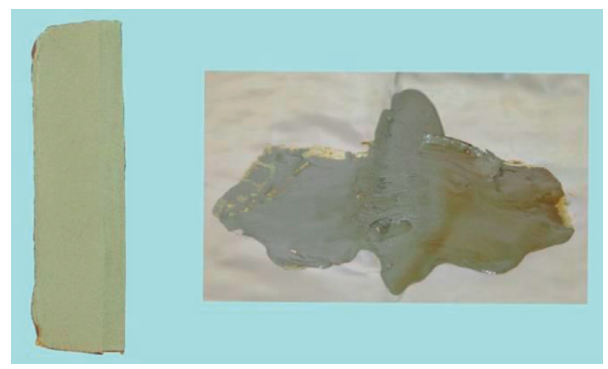

FIGURE 8: The sketch of structural failure caused by aging and decomposition of NEPE.

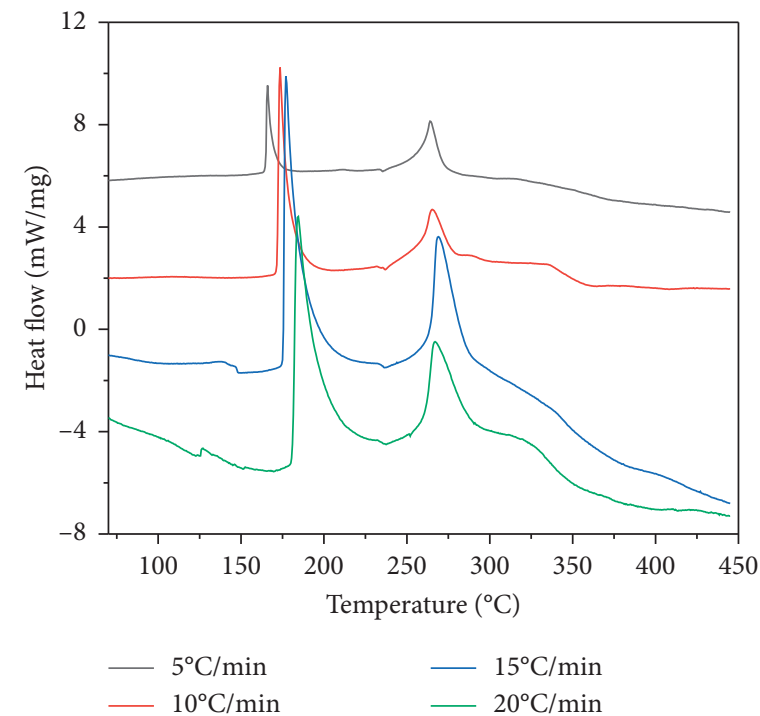

(a)

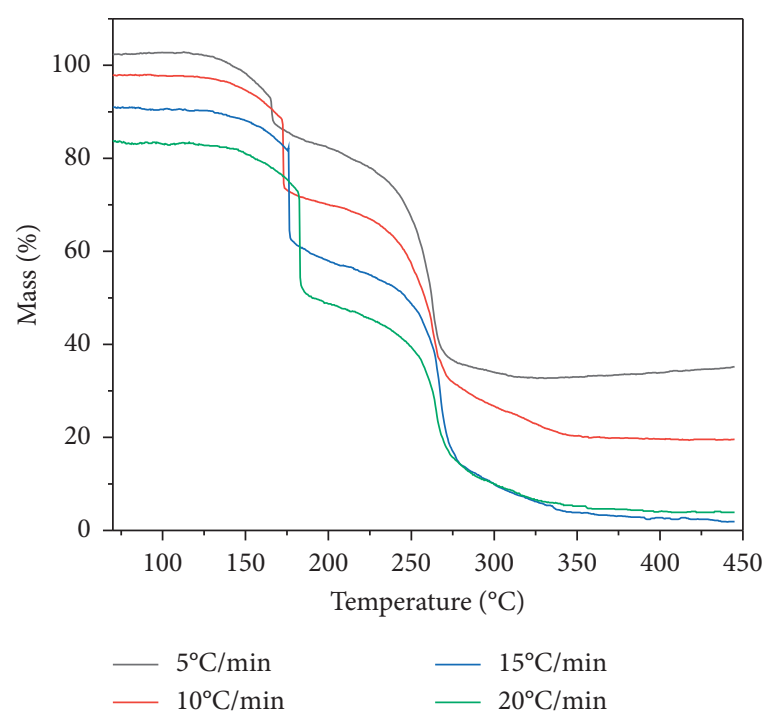

(b)

Figure 9: DSC and TG curves of NEPE at different heating rates 
the first stage of decomposition. This illustrates that the thermal decomposition of mixed nitrate is affected by the heating rate. The endothermic peak at $237.9^{\circ} \mathrm{C}$ is the crystal transformation peak of AP. The second exothermic peak is mainly the decomposition of the binder, and the weight loss rates under different heating rates are about $42 \%$. Therefore, the decomposition of the binder and heating rate are irrelevant.

\section{Conclusion}

In this work, the mechanical properties, changes in the components, weight loss, adhesive network structure fracture test, degradation reaction, and thermal decomposition of NEPE were researched in the process of accelerated storage. At different storage temperatures, as the storage time prolongs, the maximum tensile strength, maximum elongation, stabilizer content, mixed nitrate content, weight loss rate, and other parameters all show great variation rules, which can be used as propellant storage health monitoring indicators. The decomposition of the components in the propellant leads to the degradation of the PEG network structure. The thermal decomposition of the nitrate plasticizer in NEPE propellants will cause the decomposition of the adhesive network structure, which leads to chain breakage, resulting in damage to the matrix structure. The degradation of the NEPE propellant is caused by the decomposition of nitrate, and $\mathrm{NO}_{\mathrm{x}}$ is mainly produced by the decomposition of nitrate. $\mathrm{NO}_{\mathrm{x}}$ can be used as a characteristic gas for the health characterization of the propellant.

\section{Data Availability}

The data used to support the findings of this study are included within the article.

\section{Conflicts of Interest}

The authors declare that they have no conflicts of interest.

\section{References}

[1] Y. Xing and K. Dong, "Development and prospect of research on life prediction of solid rocket motors," Journal of Solid Rocket Technology, vol. 24, no. 3, pp. 30-33, 2001.

[2] K. M. Ide, S.-Y. Ho, and D. R. G. Williams, "Fracture behaviour of accelerated aged solid rocket propellants," Journal of Materials Science, vol. 34, no. 17, pp. 4209-4218, 1999.

[3] H. Xie, W. Zhou, and X. Wu, "Research progress on life prediction methods of solid rocket motors," Journal of Solid Rocket Technology, vol. 42, no. 3, pp. 377-395, 2019.

[4] D. Zhou, X. Liu, and P. Zhang, "Study on probability storage life prediction of solid rocket motor grain under constant strain," Journal of Propulsion Technology, vol. 40, no. 9, pp. 2121-2129, 2019.

[5] X. Xu, Y. Ding, and T. Li, "Research progress of storage life estimation technology of solid rocket motor propellant," Journal of Ordnance Equipment Engineering, vol. 40, no. 04, pp. 137-140, 2019.

[6] Y. M. Milekhin, A. A Koptelov, N. I. Shishov, I. A. Koptelov, and A. A. Rogozina, "Evaporation of plasticizer from NEPE type propellant," Russian Journal of Applied Chemistry, vol. 91, no. 5, pp. 802-812, 2018.

[7] W. Xie, Z. Yu, Z. Wei et al., "Sensitivity and stability improvements of NEPE propellants by inclusion of FOX-7," Propellants Explosives Pyrotechnics, vol. 43, no. 3, 2018.

[8] Y. Sun, H. Ren, and Q. Jiao, "Comparison of thermal behaviors and decomposition kinetics of NEPE propellant before and after storage," Journal of Thermal Analysis and Calorimetry, vol. 131, no. 4, pp. 1-11, 2017.

[9] H. Zhang, S. Peng, A. Pang et al., "Coupling aging behaviors and mechanism between mechanical properties and chemical stability of NEPE propellant," Journal of Propulsion Technology, vol. 28, no. 3, pp. 327-332, 2007.

[10] K. Dong, L. Pei, and L. Kong, "Aging performance of NEPE propellant under constant strain," Journal of Solid Rocket Technology, vol. 42, no. 3, pp. 403-408, 2019.

[11] A. Jing, L. Ding, and Y. Liang, "Aging performance of NEPE propellant under temperature and pressure loading," Chinese Journal of Explosives \& Propellants.vol. 42, no. 4, pp. 375-379, 2019. 